\title{
AN EXAMINATION OF INTERANNUAL POPULATION VARIATION IN PARNASSIUS CLODIUS BUTTERFLIES
}

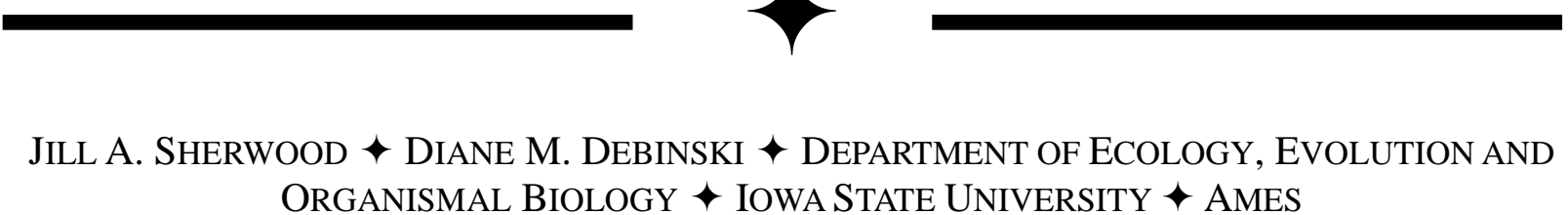
ORGANISMAL BIOLOGY $\downarrow$ IOWA STATE UNIVERSITY $\downarrow$ AMES

\begin{abstract}
$\uparrow \quad$ ABSTRACT
Examining how population size and structure vary over time is an important part of understanding how environmental factors influence a particular species. Organisms in which multiple generations can be studied in a short period of time are useful when attempting to predict the consequences of such changes. Insects, and in particular butterflies, have a short generation time, which makes them ideal for studying the effects of environmental change on demographics.
\end{abstract}

In this study, we examine the population dynamics of a butterfly common in the Teton area, Clodius Parnassian (Parnassius clodius). This area was initially studied starting in 1998-2000 (Auckland et al. 2004) and surveys were continued in 2009 2011. Emergence date varied between years by as much as three weeks. In addition, peak flight and end of flight dates also varied. Preliminary examination of the population data reveals similar patterns across years, where male emergence occurred prior to female emergence. In addition, sex ratios were also fairly consistent between years. Variation among years is observed primarily in the total number of butterflies marked and recaptured. Further data analyses comparing demographic parameters such as survival and population size need to be performed before any additional conclusions can be made. This study will add additional data to an ongoing study of the potential effects of environmental change on a common species of butterfly (Parnassius clodius).

\section{INTRODUCTION}

Populations fluctuate both spatially and temporally because of direct and indirect factors that influence their survival and reproduction. It is important to study populations and quantify these fluctuations in order to more thoroughly understand how the organisms respond to certain environmental parameters. Butterflies are particularly useful organisms for such studies because multiple generations can be studied in short period of time. Therefore, the population dynamics of butterflies could be useful indicators of the effects of environmental change on population dynamics.

Clodius Parnassian (Parnassius clodius) butterflies are univoltine, meaning that they have one generation per year. Butterflies overwinter as first star instar larvae and emerge in the spring shortly after snowmelt (Scott 1986). Larval development continues through May into June. Adults usually emerge close to the end of June/early July. The adult flight period averages $2-3$ weeks in length. Males typically emerge first and are followed by females. The success of these butterfly populations is influenced by multiple factors including the timing of the snow melt, the exposure to frosts, the emergence of food plants important to the butterflies, and the timing of male/female emergence. A disturbance to any of these factors or a change in the timing of emergence of butterflies could lead to fluctuations in population size. We studied a population of Parnassius clodius butterflies to quantify interannual variation in population size using a mark-releaserecapture survey in Grand Teton National Park during 2009-2011. Data from previous studies (Auckland et al. 2004) were combined with the more recent data to study population variation among years. The objectives of this research included surveying the adult population to determine population size, examining and comparing the emergence times between male and female $P$. clodius 
butterflies, and determining the number of unmated females at the end of the flight season.

\section{$\uparrow \quad$ METHODS}

A mark-recapture study on a population of $P$. clodius butterflies in Grand Teton National Park, Wyoming was performed from 2009-2011. Six 50 x 50 -meter plots were randomly sampled daily in 2009-2011 in a relatively flat sagebrush meadow located in Grand Teton National Park. The plots were located approximately 200 meters apart at an elevation of $2100 \mathrm{~m}$. Surveys began shortly after the first butterflies emerged and were terminated when no butterflies were seen in the plots. During a survey, two people continuously walked around within a plot to survey butterflies for a total of 20 minutes. Surveys were limited to times between 10:00 and 17:00 hours and when the temperature was above $21^{\circ} \mathrm{C}$, wind was $<16 \mathrm{kmh}^{-1}$, and the sun was not obscured by clouds.

Butterflies were captured using butterfly nets and placed in glassine envelopes until the end of the survey time. Unmarked individuals were marked individually on the ventral side of each hindwing with unique numbers using a black permanent felttipped pen. Unique numbers were recorded for all previously marked individuals. Day, time of capture, and plot location were recorded for each individual. Individual characteristics for each butterfly were also recorded, including the sex, mating status (for females), and wing wear. Sex was determined using external morphological differences present in $P$. clodius butterflies. Female mating status was noted based on the presence or absence of a sphragus (a waxy structure deposited by the male during mating that prevents future matings) (Scott 1986). Wing wear, based on three categories (new, intermediate, and old), was used as an additional measure of age of individual butterflies. Butterflies were then released in the center of the experimental plot in which they were captured. Daily results were recorded as number of individuals captured per day, including recaptures, and number of males, unmated females, and mated females captured per day.

\section{$\uparrow \quad$ RESULTS AND DISCUSSION}

Table 1 lists the number of plots surveyed each year, the plot size, time, emergence dates, peak flight dates, and end of flight dates for all of the years. Annual flight periods varied among years with the earliest date of male butterfly emergence being June $17^{\text {th }}$ and the latest July $6^{\text {th }}$. Female emergence occurred $1-3$ days after males. Peak flight times and end of season flight also varied with emergence. In addition, peak flight for females was usually 2-4 days later than that of males. End of flight for both females and males was close to the same time. Total annual flight period varied from 11 days to 18 days.

Table 1. Summary of surveys efforts in $1998-2000$ and $2009-2011$.

\begin{tabular}{|c|c|c|c|c|c|c|}
\hline$\underset{ه}{\stackrel{\leftrightarrow}{\sharp}}$ & 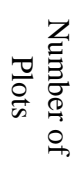 & 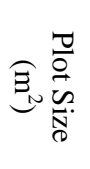 & 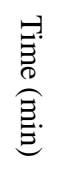 & 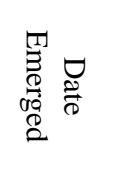 & 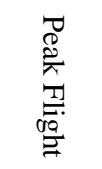 & 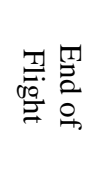 \\
\hline 1998 & 3 & 75 & 35 & 30-Jun & 7-Jul & 10-Jul \\
\hline 1999 & 8 & 50 & 20 & 28-Jun & 3-Jul & 15-Jul \\
\hline 2000 & 6 & 50 & 20 & 17-Jun & 22-Jun & 2-Jul \\
\hline 2009 & 6 & 50 & 20 & 24-Jun & 2-Jul & 12-Jul \\
\hline 2010 & 6 & 50 & 20 & 4-Jul & 7-Jul & 15-Jul \\
\hline 2011 & 6 & 50 & 20 & 6-Jul & 11-Jul & 18-Jul \\
\hline
\end{tabular}

The total number of butterflies captured varied among the years. Table 2 gives a summary of the number of male and females captured, the total number captured and recaptured, and the recapture rate. The lowest number of males (143) captured occurred in 2011 while the greatest number were caught in 2009 (651). 2011 and 2009 also had the lowest (55) and highest (187) number of females captured, as well. The same number of females was captured in 2010 and 2011 (55).

Recapture rates for males varied from $10 \%$ to $60 \%$ for males and $3 \%$ to $16 \%$ for females. In years with lower population numbers, recapture rates were usually higher. In addition, the sex ratio captured favored males in each year. The proportion of male to female captures fluctuated year to year with ranges from $4.2: 1$ to $2.4: 1$ with new captures, and approximately 9:1 in the number recaptured. The ratio of individuals captured was always male-biased, potentially due to the differences in behavior between males and females. Males patrol for females and nectar while females stay closer to ground searching for oviposition sites or nectaring on flower. As the flight period progressed, the percentage of mated females increased consistently across the years.

\section{DISCUSSION}

Preliminary results from the comparison of data from 1998 - 2000 and 2009 - 2011 reveal 
several differences in emergence date, peak numbers captured, end of flight dates, total number of $P$. clodius captured, recapture rates overall and recapture rate by sex. It is important to note that there were some differences in plot size and number of plots among years, so this will need to be taken into consideration to fully assess differences in population size estimates. Further analysis on population size and survivability between years will add to the knowledge gained from these studies. Once these data are analyzed, we can use the results to tease out factors that might be affecting populations over time, such as environmental changes. Snow cover, snow melt date, growing degree days, and frost days are a few important environmental elements that could add to the understanding of why populations vary from year to year.

Table 2. The number of Parnassius clodius captured and recaptured in all plots during surveys 1998-2000 and 2009 -2011 .

\begin{tabular}{|c|c|c|c|c|}
\hline & & Males & Females & Total \\
\hline \multirow[t]{3}{*}{1998} & Captured & 404 & 96 & 500 \\
\hline & Recaptured & 107 & 12 & 119 \\
\hline & \%Recaptured & 26 & 13 & 24 \\
\hline \multirow[t]{3}{*}{1999} & Captured & 552 & 223 & 775 \\
\hline & Recaptured & 55 & 6 & 61 \\
\hline & \%Recaptured & 10 & 3 & 8 \\
\hline \multirow[t]{3}{*}{2000} & Captured & 343 & 145 & 488 \\
\hline & Recaptured & 77 & 8 & 85 \\
\hline & \%Recaptured & 22 & 6 & 17 \\
\hline \multirow[t]{3}{*}{2009} & Captured & 651 & 187 & 838 \\
\hline & Recaptured & 187 & 22 & 209 \\
\hline & \%Recaptured & 29 & 12 & 25 \\
\hline \multirow[t]{3}{*}{2010} & Captured & 154 & 55 & 209 \\
\hline & Recaptured & 72 & 9 & 81 \\
\hline & $\%$ Recaptured & 47 & 16 & 39 \\
\hline \multirow[t]{3}{*}{2011} & Captured & 143 & 55 & 198 \\
\hline & Recaptured & 86 & 9 & 95 \\
\hline & \%Recaptured & 60 & 16 & 48 \\
\hline
\end{tabular}

\section{ACKNOWLEDGEMENTS}

This material is based upon research supported by the Xerces Society, the Center for Global and Regional Environmental Research, and University of Wyoming National Park Service Research Station. David Nelson, Melissa Kyer, Annie Binder, Susan Cable, Lauren Miller, and Zoe Pritchard assisted with data collection for the markrelease-recapture studies.

\section{$\uparrow \quad$ Literature Cited}

Auckland JN, Debinski DM, Clark WR. 2004. Survival, movement and resource use of the butterfly Parnassius clodius. Ecological Entomology. 29:139-149.

Scott JA. The Butterflies of North America. Stanford, (CA): Stanford University Press; 1986. 